\title{
Qual é o Potencial Pandémico dos Vírus Emergentes?
}

\author{
What is the Pandemic Potential of Emerging Viruses?
}

Paulo CRUZ PAIXÃO $\bowtie 1$

Acta Med Port 2022 Jan;35(1):1-2 - https://doi.org/10.20344/amp.17633

Palavras-chave: Doenças Transmissíveis Emergentes; Pandemia

Keywords: Communicable Diseases, Emerging; Pandemics

As pandemias fazem parte da nossa História, sendo o seu impacto muitas vezes superior ao de qualquer outro evento nocivo para a Humanidade, como as guerras ou as catástrofes naturais. A pandemia de gripe em 1918-19, com pelo menos 50 milhões de mortes num espaço de tempo relativamente curto, a peste e a varíola, com números difíceis de estimar, mas seguramente catastróficos para a nossa espécie, são dos exemplos mais citados quando queremos fazer a abordagem histórica do tema. ${ }^{1}$

Depois da pandemia causada pelo vírus da gripe H1N1 em 2009-2010, que causou grande alarme inicial, mas acabou por ter um impacto relativamente baixo, ${ }^{2}$ a ideia que prevaleceu nas populações foi de que esta questão das pandemias era bastante empolada pelos especialistas e pelas autoridades de saúde internacionais e nacionais. Por outro lado, cresceu a convicção de que os desafios futuros passam pelas doenças crónicas e que o papel das doenças infeciosas será cada vez mais residual, o que parece justificar o ceticismo com que grande parte da população encarou o início da presente pandemia. No entanto, a COVID-19 veio expor uma cruel realidade, a de que nossa ciência ainda é limitada para lidar convenientemente com algumas das maiores ameaças à Humanidade, sejam elas vulcões, tufões ou pandemias virais. Contudo, a ciência também tem as suas vitórias, e certamente que a maioria de nós concordará que a vacinação para a COVID-19 foi/é disso um grande exemplo.

Mas será que o que aprendemos até agora com a COVID-19 poderá ser útil numa pandemia futura? Vamos de novo recorrer à história: o que têm de comum as grandes pandemias do passado e a do presente - as da peste, varíola, gripe e, claro, da COVID-19? A resposta é inequívoca: a transmissão respiratória (por gotículas e aerossóis). E se é verdade que a peste bubónica é transmitida por pulgas, a peste pneumónica terá provavelmente sido a responsável pela rápida disseminação da peste em muitas das zonas atingidas. ${ }^{3}$ Não incluiremos aqui a infeção VIH/ SIDA, causadora de uma pandemia importantíssima mas com uma evolução lenta, fora do contexto destas pandemias de atingimento rápido da população mundial. ${ }^{4}$

A transmissão respiratória é, como a presente pande-

mia o tem demonstrado, muito difícil de evitar, implicando medidas tão rigorosas como os confinamentos a que assistimos recentemente. ${ }^{5} \mathrm{Se}$ olharmos para as outras formas de transmissão, rapidamente percebemos que, por muito importantes que possam ser a nível local ou mesmo regional, dificilmente poderão originar uma situação pandémica global.

Vejamos a transmissão fecal-oral, por exemplo no caso da cólera: ainda hoje origina surtos importantíssimos em certas zonas do globo mas o saneamento básico consegue, nos países onde se encontra disponível, controlar os avanços causados pelo Vibrio cholerae. ${ }^{6}$

Por outro lado, a transmissão sexual, pode também efetivamente originar pandemias, mas como já referimos anteriormente a propósito da infeção VIH/SIDA, não tem capacidade de o fazer de uma forma rápida. ${ }^{7}$

Já a transmissão pelo contato direto com doentes infetados, como acontece com a infeção pelo Ébola, pode ser difícil de controlar, sobretudo em determinados contextos sociais e económicos. Contudo, a implementação de medidas rigorosas acabará por ser bem sucedida antes que adquira caráter pandémico, tal como se tem verificado nos diferentes surtos epidémicos causados por este vírus. ${ }^{8}$

Quanto a um outro agente emergente, o vírus Nipah, que esporadicamente é noticiado como causador de surtos em certas regiões do mundo, o seu potencial pandémico pode ser limitado pela transmissão predominante através de contato com animais infetados, sobretudo porcos e morcegos, não sendo a transmissão inter-humana muito eficaz. No entanto, deverá ser uma situação para acompanhar no futuro. ${ }^{9}$

Mas afinal onde estarão as origens das próximas pandemias? Pelo que já foi dito, e com base na experiência do passado, os grandes candidatos ao título serão, claro, os vírus respiratórios. Na nossa opinião, estes últimos serão seguidos, muito provavelmente, pelos arbovírus (arthropod-borne virus), vírus transmitidos por mosquitos. A lista deste tipo de ameaças é longa, umas mais mediáticas do que outras, e inclui os vírus do dengue, zika, chikungunya, o vírus da encefalite japonesa e o vírus do Nilo Ocidental. As alterações climáticas estão a facilitar a disseminação

\footnotetext{
1. Faculdade de Ciências Médicas. Universidade NOVA de Lisboa. Lisboa. Portugal.

$\square$ Autor correspondente: Paulo Cruz Paixão.paulo.paixao@nms.unl.pt

Recebido: 04 de dezembro de 2021 - Aceite: 06 de dezembro de 2021 - Online issue published: 03 de janeiro de 2022

Copyright $\odot$ Ordem dos Médicos 2022
} 
de espécies de mosquitos transmissoras destes vírus, pelo que bastará vermos a evolução na Europa do Aedes albopictus (mosquito que pode transmitir, entre outras, os vírus do dengue ou chikungunya) nos últimos anos, ou o que aconteceu com o vírus do Nilo Ocidental nos Estados Unidos da América, para percebermos que esta ameaça é real e que dentro de um prazo relativamente curto poderemos ter epidemias por estes vírus em zonas onde anteriormente nunca suspeitaríamos que isso pudesse acontecer. ${ }^{10}$

Terminamos com a questão inicial: será a transmissão respiratória inter-humana de vírus a forma catalisadora de uma futura pandemia? De que vírus respiratórios estamos a falar? Os vírus da gripe (intencionalmente no plural) são sempre fortes candidatos, podendo a ameaça surgir sob várias formas. Uma delas, aquela que mais receio tem suscitado, seria uma pandemia de um vírus causador de gripe aviária capaz de atravessar a barreira de espécies. Esta questão pode ser analisada sob duas perspetivas diferentes: por um lado, a má notícia é que estes vírus já existem: falamos do famoso H5N1, mas existem outros, com menor notoriedade e já capazes de infetar diretamente o homem, em geral com taxas de mortalidade muito mais elevadas que a COVID-19 (a taxa de mortalidade para o H5N1 está acima dos $50 \%) .{ }^{11}$ Por outro lado, a boa notícia é que, até agora, a transmissão inter-humana não se efetuou de uma forma eficaz. Por fim, não devemos também descartar outros vírus da gripe, como por exemplo algumas variantes originárias dos suínos, que poderão mais facilmente fazer o trajeto inter-espécies e originar uma epidemia de larga escala. $^{12}$

E os coronavírus? Relembremos que mesmo antes da COVID-19 os coronavírus já tinham suscitado algum alarme, quer com o SARS-CoV-1, que como sabemos foi rapidamente dominado, quer com o MERS-CoV, associado ao

\section{REFERÊNCIAS}

1. Piret J, Boivin G. Pandemics throughout history. Front Microbiol. 2020;11:631736.

2. Roychoudhury S, Das A, Sengupta P, Dutta S, Roychoudhury S, Choudhury AP, et al. Viral pandemics of the last four decades: pathophysiology, health impacts and perspectives. Int J Environ Res Public Health. 2020;17:9411.

3. Raoult D, Mouffok N, Bitam I, Piarroux R, Drancourt M. Plague: history and contemporary analysis. J Infect. 2013;66:18-26.

4. Fischer W, Giorgi EE, Chakraborty S, Nguyen K, Bhattacharya T, Theiler J, et al. HIV-1 and SARS-CoV-2: patterns in the evolution of two pandemic pathogens. Cell Host Microbe. 2021;29:1093-110.

5. Halperin DT, Hearst N, Hodgins S, Bailey RC, Klausner JD, Jackson H, et al. Revisiting COVID-19 policies: 10 evidence-based recommendations for where to go from here. BMC Public Health. 2021;21:2084.

6. D'Mello-Guyett L, Gallandat K, Van den Bergh R, Taylor D, Bulit G, Legros $D$, et al. Prevention and control of cholera with household and community water, sanitation and hygiene (WASH) interventions: a scoping review of current international guidelines. PLoS One. 2020;15:e0226549.

7. Sobia P, Archary D. Preventive HIV vaccines-leveraging on lessons
Médio Oriente e aos camelos dromedários - e se esta curiosa associação com os camelos até nos pode fazer sorrir, a mortalidade descrita de $30 \%$ e a possibilidade de transmissão inter-humana nada têm de divertido. Felizmente, a monitorização desta situação tem revelado que embora a transmissão inter-humana exista, não se tem revelado muito eficaz. ${ }^{13}$ Contudo, o próprio SARS-CoV-2, através da sua capacidade de adaptação ao ser humano e de alteração genética, poderá constituir uma ameaça futura, sob forma de alguma variante mais transmissível e/ou mais resistente à resposta imunitária pós-vacinação, não esquecendo que no seu reservatório natural (morcegos), existem ainda muitos outros 'primos' com potencial para nos afectar. ${ }^{14}$

Em suma, os vírus respiratórios, nomeadamente os da gripe e os coronavírus, estão, na nossa opinião, claramente na pole position para uma futura pandemia. Os arbovírus e, eventualmente, outros vírus emergentes, como o Nipah, deverão igualmente ser monitorizados nos anos vindouros apesar da menor probabilidade de causarem pandemias. Deverão preparar-se e divulgar-se planos de preparação pandémica que considerem estas diferentes possibilidades, com a brevidade possível, de forma a que se reaja de forma mais proactiva e imediata numa próxima situação semelhante.

\section{CONFLITOS DE INTERESSE}

O autor declara não ter conflitos de interesse relacionados com o presente trabalho.

\section{FONTES DE FINANCIAMENTO}

Este trabalho não recebeu qualquer tipo de suporte financeiro de nenhuma entidade no domínio público ou privado.

from the past to pave the way forward. Vaccines. 2021;9:1001.

8. Sharma AR, Lee YH, Nath S, Lee SS. Recent developments and strategies of Ebola virus vaccines. Curr Opin Pharmacol. 2021;60:4653.

9. Singhai M, Jain R, Jain S, Bala M, Singh S, Goyal R. Nipah virus disease: recent perspective and One Health approach. Ann Glob Health. 2021;87:102.

10. Mayer SV, Tesh RB, Vasilakis N. The emergence of arthropod-borne viral diseases: a global prospective on dengue, chikungunya and zika fevers. Acta Trop. 2017;166:155-63.

11. Poovorawan Y, Pyungporn S, Prachayangprecha S, Makkoch J. Global alert to avian influenza virus infection: From H5N1 to H7N9. Pathog Glob Health. 2013;107: 217-23.

12. Judson SD, Rabinowitz PM. Zoonoses and global epidemics. Curr Opin Infect Dis. 2021;34:385-92.

13. Willman M, Kobasa D, Kindrachuk J. A comparative analysis of factors influencing two outbreaks of Middle Eastern Respiratory Syndrome (MERS) in Saudi Arabia and South Korea. Viruses. 2019;11:1119.

14. Wong AC, Lau SK, Woo PC. Interspecies jumping of bat coronaviruses. Viruses. 2021;13:2188. 